\title{
From Status of Experts to Status of Surfers: A New Approach of Social Practices on the Internet
}

\section{Martin $\mathbf{M}^{*}$}

University of Reunion Island, France

${ }^{*}$ Corresponding author: Martin M, Associate Researcher, Oracle Laboratory, University of Reunion Island, France, Tel: +262 262 93 80 80; E-mail: marcienne.martin@hotmail.com

Received date: September 18, 2017; Accepted date: September 25, 2017; Published date: October 4, 2017

Copyright: 2017 @ Martin M. This is an open-access article distributed under the terms of the Creative Commons Attribution License, which permits unrestricted use, distribution, and reproduction in any medium, provided the original author and source are credited.

\begin{abstract}
The Technologies of Information and Communication (TIC) are responsible for the development of innovative paradigms. Thus, the Internet allows users to communicate by overcoming geographical frontiers. This access to everything and everyone also opens on another phenomenon like, for some users, to invest themselves in missions usually reserved for experts. This is the prescriptive roles that arrogate to themselves certain groups of users who then try to take the place of agencies duly authorized to act in a particular subject area.
\end{abstract}

Keywords: Technologies of information and communication; Expertise; Surfers; Internet

\section{Introduction}

At the user of the Internet media, behaviours differ from those in progress in civil society. From previous work and on the basis of surveys made online, I found several phenomena. On the one hand, with the aim to confirm or refute the assumptions, including but not confirmed proxemic distance phenomenon that is the cause of the levelling of the hierarchy on the Internet and, secondly, to understand the onomastic construction of the pseudonym on the Internet, three types of surveys will be established, whose results have been the subject of the book 'Se nommer pour exister - Lexemple du pseudonyme sur Internet' (A Name to Exist: The Example of the Pseudonym on the Internet).

Concerning the second investigation, it had covered the construction of the pseudonym of forums and chat rooms and has been put online by the IDRAC Montpellier business school. This study has been made on the basis of a population of about 1000 users. In establishing this questionnaire, we will introduce different variables, such as gender, age and level of education, as well as the items proposed in the nomenclature of French activities of the INSEE (1); Thus: 'Questions 19 and 20 refer to the concept of pertinent hierarchy in civil society. These questions are formulated as follows: "Do you feel that there is a hierarchy between you and some users (knowledge, supposed personality, other seduction criteria, etc.)?" And "If so, could you explain in a few words." 1063 people responded to question 19. They are divided as follows: $22 \%$ (229) responded with an affirmative, while $78 \%$ (834) said no. $78 \%$ is particularly interesting, because it shows that situation such as the current hierarchy in civil society, are not transferred ipso facto in society virtual. 229 users responded positively to the question.'

The Technologies of Information and Communication (TIC) are responsible for the development of innovative paradigms. Thus, the Internet allows users to communicate by overcoming geographical frontiers. This access to everything and everyone also opens on another phenomenon like, for some users, to invest themselves in missions usually reserved for experts. This is the prescriptive roles that arrogate to themselves certain groups of users who then try to take the place of agencies duly authorised to act in a particular subject area. In the present article, it will be presented and discussed the creation of lexical entries online as well as that of collaborative dictionaries. In the first paragraph it will analyse new modes of Internet behaviour in particular through the organisational phenomenon. This is corroborated by the finding of the levelling of the hierarchy on this media with, as a corollary, the widespread use of the informal language in place of the formal one, which can open the creation of expertise on the part of people who would never have had this role in civil society. Concerning the phenomena of expertise, in the second paragraph, it will be presented different examples of lexical units created by Net surfers and extracted from dictionaries called 'collaborative dictionaries'.

Several questions arise from these social practices. Is there any correlation between the levelling of the hierarchy and the role played by expert users whose skills are not valid in civil society? Otherwise, on which kind of model is built the praxis in civil society? What impact can have, in the virtual society and civil society, the creation of neologisms by Internet users investing the status of taxonomists and that of the lexicographer, but does not possess it?

\section{The Organizational Systems as the Basis of Group Cohesion}

In order to understand better how a user can affirm to have expert status without having the training or the skills, we will attempt to identify the differences between civil society and digital society which have the common characteristic of being composed groups of individuals. Convene the group concept refers to the lexical following definition: 'ensemble of people or things put together in the same place or set of people with a common point (opinions, tastes...)'. The concept of group is defined as a multitude of interpersonal relationships structured around a goal for the common interests' [1]. These authors state that this structure 'arises from the collective pressure of a need experienced by each individual as a lack, an imbalance which is translated in a gesture, an act that seeks opportunities to satisfy this 
need from what he perceives in the physical and social environment [1]. Other specialists of this discipline say that they 'may be satisfied with mutual adjustment to coordinate their activities' [2]. Note also that: in order to run, the organisation creates so-called formal groups, consisting of one person taking a role of authority (the supervisor) and many people assuming the role of subordinated'[1]. Also: 'For that the group has some permanence, individuals must adhere to the common objective or focus on one person in the group that represents the collective ideal' [3].

Describes the organisational universe in the form of metaphors. Thus, the mechanistic view of the organisation can also be understood as a body, a brain, a culture, a political system. The interpenetration of different aspects of the mode of organisation of living or derived from living forms a complex multi-organisational. Thus, whatever the nature of the group, formal or informal, its operation is correlated with a specific structure.

Hogue, Levesque and Morin mention too: 'When size increases and that structure is deployed in multiple functions, communication networks are created and the authority structure is emerging. The group became institution or bureaucracy; relationships with individuals become asymmetric in the sense that some have more power than others and can then submit them to their special interests'. According to studies [4], the growth of the organisation has resulted in the establishment of management structures associated with the development of a hierarchy of authority. This analysis was made at the enterprise level; it is also applicable to other sectors of human activity whose goal is not necessarily the production of tangible or intangible assets on the market. Regarding the notion of power arising from asymmetrical relations between groups or individuals, Crozier and Friedberg specify that it always implies the possibility of individuals or groups to act on other individuals or groups' [5-7].

In this type of organisational structure, the markers of authority, for example, are realised in conversational procedures such as prescription or order, with such phrases as: 'You are invited to.... Menier and Laflamme have identified five sources of power including the power of expertise that is based 'on the knowledge or specific information available to an individual' [8]. As for the notion of expertise itself, Dionne shows that it is underpinned by the use of jargon as well as by the establishment of certain communicative modes: 'The construction of meaning through rituals known... Everyone addresses communication through his own perception, through a filter which leads naturally to select information, to build his version of reality, its truth... The effect is even more noticeable in multidisciplinary teams who have to deal with complex issues; both specialised areas provide fertile ground for these truths. Because of his role, the specialist tends to act spontaneously in this direction. Each specialty is in a particular frame of reference [9]".
If the digital society has its roots in civil society, it does not mean that it is a replica: it is only a partial representation. For example, the transformation of the notion of time is not the same as used in civil society; the time on the Internet is centered on the temporal immediateness. The Internet media composed of both of an area of digital data correlated to a set of interconnected computers and of individuals managing the operation, differs from civil society for all offered services only accessible by the use of artifacts, including the microcomputer. The Internet is at the crossroads of two phenomena that were opposed to one another both in their concepts as social practices that result [10]. This is the anonymity and privacy. On forums and in chat rooms, communicative codes in place also different from those existing in civil society: the hierarchy is no longer valid, the 'tu' (familiarity) in French language is used mostly and each Internet user can expose, through the creation of Web pages or, even, for that of its inscription on social networks, passions, skills, etc.

The access to the Internet which includes the communication with much of the world is dependent on a machine, the computer, since no Internet user can browse the web without this technology. This object is located, for much of Internet users, at home, at least in France; a study of INSEE corroborates this phenomenon: 'The network of family and friends is more requested that of the public places: a quarter of the population is already connected with friends, neighbours or family and only one tenth in an internet cafe, internet shop, a library...' [11]. Finally, the user is registered, both within an organisation in groups, set up within a particular spatiality: each behind his machine keeping a physical distance almost uniform, and is also in its intimate space, since very often the use of the computer is a praxis that takes place at his home. In addition, it uses the Internet in its place of work or study, the user is always located in its personal sphere. This factor may be the source of contradiction between identity having the form of anonymity, but betraying signs of what [12]. Refer to as 'Espace Élémentaire d'Identité Sociale' [E.E.I.S] [13]. The digital society is composed of formal groups and informal groups, composed of individuals who do not know each, who form and break up at the mercy of the discussions.

The concept of proxemic distance has been theorised by Hall and it hinges on two factors: first, concerning the physical territory as a place of communicative exchange, because 'man also observes uniform distances in his relationship with others' [14]. And second, the division of observed distances between two subjects placed in a communication situation. These distances are listed as follows: intimate distance (direct contact with $\sim 0.45 \mathrm{~m}$ ), personal distance $(0.45 \mathrm{~m}$ to $1.25 \mathrm{~m}$ ), social distance $(1.25 \mathrm{~m}$ to $3.60 \mathrm{~m})$ and finally, public distance $(3.60 \mathrm{~m}$ and beyond). He argues that regardless of socio-cultural environment, 'the personal and social distances always exist' (Table 1) [15-17].

\begin{tabular}{|l|l|l|l|}
\hline \multicolumn{2}{|l|}{ Personal space } & \multicolumn{2}{l|}{ Social space } \\
\hline Intimate distance & Personal distance & Social distance & Public distance \\
\hline from direct contact with $\sim 0.45 \mathrm{~m}$ & from $0.45 \mathrm{~m}$ to $1.25 \mathrm{~m}$ & from $1.25 \mathrm{~m}$ to $3.60 \mathrm{~m}$ & from $3.60 \mathrm{~m}$ and beyond \\
\hline
\end{tabular}

Table 1: Proxemic distances theorised by T. hall.

On the Internet, it seems that there is telescoping between actual physical distance common to all users, private space where is located the Net surfer and which allows him to access to the digital sphere, the symbolic distance existing between the user and its correspondent and the representation of this media has every Net surfer and who is peculiar to him. 
In order to preserve their anonymity and guarantee their security, Web users take a pseudonym, a nomination that can let through or not some indications of their real identity. In addition, rules have been put in place to keep this space as friendly and courteous, 'the Internet calls these rules of behaviour: the Netiquette, a word created from the terms: Net and etiquette' [18]. Moreover, the author underlines: 'Even if no laws, no prohibition limits the creative chaos that reigns over the Internet, follow the basic rules and friendly precepts. This is simply to implement the practices generally observed in human societies. Rule number one on the network is: Act on the Internet like you do elsewhere in public, particularly egoist behaviour is contrary to this rule' [19].

Other phenomena seem to corroborate the fact that certain social practices developed on the Internet refers to the personal space of the user. In this regard, a study on line and aiming Internet users were conducted previously [20]. The questionnaire was developed around the construction of the pseudonym and it was asked to the interviewee to explain how he created his autonym. Composed of closed questions, of multiple choice questions and of open questions, this survey was organised around several thematic classes, divided themselves into subclasses. The numbers given in previous studies [21] show that on 300 respondents (survey population) 'thematic classes grouping the choice of interviewees is as follows: 139 subjects chose the thematic class named "personal history of the subject", while all of the other two thematic classes named respectively "objects societal" and "indices of the subject's personality", have been solicited by 145 interviewed' [22]. A more refined analysis of the thematic class that collects the greatest number of choices as a support of onomastic creation, highlights the fact that it concerns objects that affect the privacy of the subject (over $50 \%$ of pseudonyms). As outlined in the above work: 'the establishment of nomen falsum can be realised through existing identities: updating of surnames or given names, anthroponyms referring to the personal history of the user and thus indirectly to his entourage, creating autonyms as metaphorical or encrypted form [23]'.

The pseudonyms presented in Table 2 are extracted from the corpus of the questionnaire responses and are showing the integration of elements of privacy inside the public sphere as part of the digital society.

For ZOUZOUTE: 'use of such names by the family';

For Marthe: 'I wanted to be myself. My name is Martha, I took the name of Laura for three months, then I took over my first name';

for MariaLuna: 'My middle name is Marie-Anne, I was born under the influence of the moon and my origins are Spanish of side my father';

For LN33: 'Just because In, this is my first name Helen and 33, where I come from Bordeaux';

For Malinche: 'it concerns our family history';

For MacLamy: 'combination of my maiden name and of my married name';

For Ju: 'diminutive of friends';

FOR brimbelle7: 'it's a nickname which was given to me longtime';

For PM: 'PM are the initials of my name and the nickname I have'.

Table 2: Some examples of pseudonyms transferred from the privacy of Internet users to the digital society.

Regarding the cryptonym, it would be a way to amplify the secret related to the nature of the pseudonym. Concerning the private sphere, some Internet users have taken some anthroponyms already in use in their family or friends such as some nicknames. Other Internet users have created pseudonyms that allow them to be recognised by their peers when they join chat rooms.

Regarding the communicational phenomenon, Corraze specifies: The social cues the most obvious, although they are not the most important, are the communicative events. This term can be applied to any organisation that has become ritualised, that is to say specialised in form and frequency as a way of adaptation specifically to convey information' [24-27]. On the Internet, the rituals of communication set up differ from that take place in civil society. In French, the realisation of politeness markers in a register of language familiar goes in the direction of a levelling of proxemic distances symbolic. In French, the use of pronouns of address marks the emotional distance: 'You/you for the familiarity, you/you for the distance' [28].

\section{The Appropriation of Expertise by Some Internet Users}

In the context of the Internet a number of common praxis have been developed as artifacts used as mediator objects having a common real and symbolic distance between all the Net surfers through the screen the computer, the identity registration through a pseudonym, the communicational exchanges usually made in a register of language familiar, the levelling of the hierarchy and, often, the subtraction of the surfer to the current rule in civil society as for example downloading music or the exchange of film which not considered as theft. Other practices are carried out in this space such as the availability for all users of knowledge and expertise often offered free of charge by some users of the Web. Why the concepts of 'experts' and of 'expertise' for the Internet? The dictionary gives of the term 'expert' the following lexical definition: 'a person who has acquired through experience great skill. As part of the redefinition of the social role of Internet users, an expert on New Technologies of Communication and Information mentions how this medium 'highlights the ease with which even a novice Internet user, and also socially anonymous can publish across the planet a personal page [29].

Thus, some users put into line dictionaries called 'collaborative dictionary' in which they are investing in the role of lexicographers and neologist. Collaborative work is particular to the digital society since it involves the collaboration of users to the achievement of group work without an employment contract or any compensation. There is no fixed division of tasks. As it is noted in the online encyclopedia 
Wikipedia: '[The collaboration] combines three methods of organisation: it offers everyone within a common project to be a part of a principle of continuous improvement of each task and of the entire project, the work is organised in parallel sequences of tasks, it offers to the participants of each task some useful and easy information'.

The results regarding the outcome of a project, sometimes defined as an approximation are not anticipated in terms of performance such as the implementation in a given time, economic benefits, etc., but rather in terms of creativity and gratuities. Internet users give to the project all their time and skills. When some users are no longer on this project, others will resume it because the project can always be improved; they will bring so their own skills and resources [30].
Based on the model the online encyclopedia Wikipedia which is a 'free draught of encyclopedia that anyone can edit', The French Jargon is a dictionary defined as 'collaborative' and who will line existing some lexical definitions that already exist well as some neologisms. All these entries are freely available by Internet. In Table 3, some examples are presented. As stated in Martin: 'These lexical corpus reflect, on the one hand, amateurism, because their implementation is purely individual, but on the other hand, they also show some expertise, since these documents were created by "resource people" who put their skills and their knowledge available to all users of the Internet [30].

\begin{tabular}{|l|l|}
\hline $\begin{array}{l}\text { Alphabarre } \\
\text { (Neologism) }\end{array}$ & $\begin{array}{l}\text { Feminine noun. [Web]. Horizontal bar that lists the letters of the alphabet behind which there are links to subsets of a larger whole, } \\
\text { each subset bringing together the elements whose name starts with the same letter of the alphabet. }\end{array}$ \\
\hline $\begin{array}{l}\text { Balado diffusion } \\
\text { (neologism) }\end{array}$ & $\begin{array}{l}\text { Feminine noun. [sound] [Society]. Contraction of 'Walkman' and 'broadcast' on the mode of 'broadcasting'. French version (and } \\
\text { widespread) of podcasting. }\end{array}$ \\
\hline $\begin{array}{l}\text { Ballado diffusion } \\
\text { (Neologism) }\end{array}$ & $\begin{array}{l}\text { Feminine noun. [Orthography]. Incorrect version of podcasting (the 'ballad' - ballade in French language - is not the root of the digital } \\
\text { music player). }\end{array}$ \\
\hline $\begin{array}{l}\text { GETA } \\
\text { (neologism) }\end{array}$ & Google [Society]. Google is your friend. French version of GIYF, often denoted GETA. \\
\hline
\end{tabular}

Table 3: Some examples of lexical entries proposed by the Internet (corpus 1).

Regarding the neologism 'podcasting', some users are intervened to denounce a neologism poorly constructed as it is shown in the correction presented below: "Wrong version of podcasting (the "ballad" - ballade in French language - is not the root of the player digital)'. The acronym GETA is a translation of the acronym GIYF (Google is your friend). In this scenario, this acronym looks like an advertising campaign that could have been initiated by the Google brand.

Le Dico du Net (Dictionary of the Net) is a collaborative dictionary which announces on its homepage: 'The Dictionary of the Net, it is also with you! Created by volunteers of the Internet, our dictionary offers the possibility of proposing the definition of an expression, of a word or of an acronym. This is then submitted to experts for approval. If successful, it is published. Any definition may be supplemented by comments following the same procedure. Each definition (and comment) contains references to its author and so enriches our common culture. 'The founders of this site are computer scientists. Initially this site was dedicated mainly to the construction of a dictionary of e-technologies, but it is now 'open to all themes' and lists all kinds of lexical entries. In Table 4 it is presented to the list of recent published definitions.

\begin{tabular}{|c|c|}
\hline $\begin{array}{l}\text { Aromatic jewel } \\
\text { Bijou aromatique (French } \\
\text { Language) }\end{array}$ & An aromatic bijou is decorated with a small flask typically used to make perfume. Author=Soap-opera (online store) \\
\hline $\begin{array}{l}\text { Cani-hiking } \\
\text { Cani-randonnée } \\
\text { (French Language) }\end{array}$ & The cani-hiking is the practice of hiking pulled by a dog. Author=Fenril. fr \\
\hline $\begin{array}{l}\text { Chauffage solaire } \\
\text { (French Language) }\end{array}$ & With a solar heating system, the main energy for heating comes from solar radiation. Author=Stephen Weiss (online store) \\
\hline $\begin{array}{l}\text { Coach in dance } \\
\text { Coach en danse } \\
\text { (French Language) }\end{array}$ & A coach in dance allows to the more timid overcome their fear of the dance floor. Author=Leenette75 \\
\hline $\begin{array}{l}\text { Leather } \\
\text { Cuir } \\
\text { (French Language) }\end{array}$ & Leather is the material obtained after the tanning of skin animal. Author=Instant Luxe (boutique en ligne) \\
\hline $\begin{array}{l}\text { Digiborigene } \\
\text { Digiborigène }\end{array}$ & The term refers to all those for whom digital spaces are living spaces. author=Yann Leroux \\
\hline
\end{tabular}




\begin{tabular}{|c|c|}
\hline (French Language) & \\
\hline $\begin{array}{l}\text { Emerald } \\
\text { Émeraude } \\
\text { (French Language) }\end{array}$ & Emerald is a very rare gem which can be found in Colombia and which is used in jewellery. Author=Instant Luxe (boutique en ligne) \\
\hline $\begin{array}{l}\text { EVJF } \\
\text { (French Language) }\end{array}$ & $\begin{array}{l}\text { Definition: To bury his life as a girl consists to celebrate the last day of celibate daughter before she was married. This day is usually } \\
\text { lived in good spirits, surrounded by her best friends. } \\
\text { Description: The Bachelor Party of a young girl, whose sign is EVJF, is a premarital custom whose goal is to offer to the future bride } \\
\text { all that his next engagement is going to forbid her afterwards. We often think of the male stripper and how he is paid as for example, } \\
\text { with as selling small items to passers by on the street, with all the disguised and masked guests. But in recent years, the EVJF can } \\
\text { also have fun with friends, always with a special role to the one that buried his celibate life. Now you can organise meetings of sex } \\
\text { toys, the removal leaf collective during workouts dance like 'Disco' or 'Oriental'; this can take all day. After a day punctuated with fun } \\
\text { games and group activities, the guests go to a restaurant then to the nightclub for dancing. Warning: the bride and groom celebrate } \\
\text { their bachelor party in separate ways. Author=Lennette75 }\end{array}$ \\
\hline $\begin{array}{l}\text { Case making } \\
\text { Rembordage } \\
\text { (French Language) }\end{array}$ & $\begin{array}{l}\text { Technique to dress up support such as a cardboard by sticking a subject or a printed on its surface and slices. Author=Jean-Michel } \\
\text { THIERION }\end{array}$ \\
\hline $\begin{array}{l}\text { Ruby } \\
\text { Rubis } \\
\text { (French Language) }\end{array}$ & $\begin{array}{l}\text { The ruby is a red gemstone which can be found mainly in mines in Africa, Asia and Australia. Author=Instant Luxe (boutique en } \\
\text { ligne) }\end{array}$ \\
\hline $\begin{array}{l}\text { Sapphire } \\
\text { Saphir } \\
\text { (French Language) }\end{array}$ & Sapphire is a gemstone that can be of different colours, blue being the most famous. Author=Instant Luxe (boutique en ligne) \\
\hline
\end{tabular}

The consultation of Table 4 shows that definitions are proposed by users who wish to invest themselves in this type of collaborative work, but also by other users who are promoting of their product under the guise of collaborative work. On the small corpus shown in the above table, we find terms accepted by the French Academy as neologisms or that lexical unit that we can find in a specialised dictionary (cases making). If we proceed with the analysis of these three groups of words, we find that for the official terms, users have given a definition which corresponds to a general approach that the majority of French speakers may have, but that stands out, however, of the definition of the French Academy (Table 5).

\begin{tabular}{|l|l|}
\hline $\begin{array}{l}\text { Leather } \\
\text { Cuir } \\
\text { (French Language) }\end{array}$ & $\begin{array}{l}\text { ATILF: Imputrescible material, relatively resistant to water, flexible, obtained by tanning process of the skin and used for various } \\
\text { purposes. Hyperonym=not mentioned. }\end{array}$ \\
\cline { 2 - 3 } $\begin{array}{l}\text { Emerald } \\
\text { Émeraude }\end{array}$ & Le dico du Net: Leather is the material obtained after the tanning of skin animals. Hyperonym=culture. \\
\hline French Language) & ATILF: Precious stone, transparent and generally a deep green, forming a variety of Beryl. Hyperonyms=mineralogy and jewellery. \\
\cline { 2 - 2 } $\begin{array}{l}\text { Ruby } \\
\text { Rubis }\end{array}$ & Le dico du Net: Emerald is a very rare gem which can be found in Colombia and which is used in jewellery. Hyperonym=culture. \\
\hline $\begin{array}{l}\text { Sapphire } \\
\text { Saphir } \\
\text { (French Language) }\end{array}$ & ATILF: precious transparent stone of a bright red belonging to a variety of corundum. Hyperonym=mineralogy. \\
\cline { 2 - 3 } & Le dico du Net: The ruby is a red gemstone which can be found mainly in mines in Africa, Asia and Australia. Hyperonym=culture. \\
\hline
\end{tabular}

Table 5: Comparison of official definitions and "collaborative" definitions.

It should also note that in the dictionary Treasury of the French Language Computer (TLFi), the hypernyms which subsuming lexical entries: emerald, ruby and sapphire are the mineralogy and the jewellery, while on the Dico du Net, they are part of the hypernym: 'culture'. The term: 'case making' belongs to a specialised lexicon of leather goods [31,32]. The online dictionary Reverso gives the following definition: cases making ('rembordage' in the French language) - masculine noun (leather goods) folding the tapered edges of leather. This dictionary is a dictionary called 'collaborative dictionary.'

Each of the proposed definitions also refers to a much more explicit description signed by the author of the lexical entry. Thus, the user Fenril. fr has proposed the lexical unit: 'Cani-hiking' built with - cani 
prefix from which is derived the term dog: 'from the Latin language canis. The author gave the following definition of this term: 'The Canihiking is the practice of hiking pulled by a dog.' It also provides this description: 'The dog wears a harness or bag pack which is attached to a leash similar to that used in cani-cross. This leash is connected either to a backpack or to a belt of cani-cross. The dog pulls his master what he allows him to browse faster routes and so discover more landscapes. This activity increasingly popular may be practised with any healthy dog, whatever his race and his size. "The Dictionary of the Net has a series of neologisms built with the prefix-cani such as: cani-cross canihiking, mountain biking-cani.

The term 'coach dancing' is defined as follows by its author, Leenette75: 'A coach in dance allows the most timid to overcome their fear of the dance floor'; this author has added a description in which we can read: 'The dance is not accessible to everyone. Many people are scared to go dancing, they give the impression of being ridiculous, not to know how to move rhythmically. However, a simple click is enough sometimes for that the person once again appreciates dancing. A coach in dance provides an opportunity, through a tailored teaching and targeted exercises, the restoration of confidence in dancing. Learning the basic steps, the acquisition of tempo and disinhibition facilitate the work of coaching.'

The lexical unit: Digiborigène refers to the English idiom: Digital Native whose meaning: digital natives or Net Generation. The description by the author, Yann Leroux, is: 'It is a translation derived from the: Digital Native, a term that Mr. Prensky uses for people who are comfortable with digital objects. For digiborigène, there is continuity between the online space and space offline. The two spaces are not opposites; they overlap and enrich each other. We are all called to become digiborigènes [33]. 'The construction of this neologism was made on the model of the term' aboriginal 'formed from' the Latin term: aborigines' (DHLF 7). In this case, the very history of the digital society is in contradiction with the construction of this neologism, which is reinforced by the clausal unit: 'We are all called to become digiborigènes' referring to a likely future, but having nothing to do anyway, with the Latin suffix origin.

\section{Conclusion}

It is clear that Net users have developed some operating modes whose creativity and lack of hierarchy seem to be the base. As we have seen, dictionaries called 'collaborative' are tools which are open to all Internet users who want to invest themselves in the role of lexicographers and of neologists. The form of 'collaborative dictionaries' is modelled on those of general and specialised dictionaries with lexical entries officials presented in alphabetical order. In contrast, the hypernyms initiating the word classes seem to be started from the mobilisation of ancient knowledge and commonly accepted. In general, and specialised dictionaries, reference to the lexical entries, correspond to any articles purely descriptive, which is not always the case for dictionaries called 'collaborative.' Thus, for the term 'dance coach', the author refers to 'the terrified of the dance floor' while the description of this neologism corresponds to that of a business and rather to the motivations that lead some people to call this specialist. It is the same for the lexical unit: 'digiborigène' where the author ends his article by: 'We are all called to become digiborigènes', phrasal unit type prescriptive. Some contributors make of confusions of sense or typing errors as in the definition of the term proposed by Lennette75: EVJF that she designates as a 'sign' and not an 'acronym'. Furthermore, we find, for example, in the Dico du Net, some proper names such as Saint Benoit de Nurcie, brand names and more specifically to that which correspond to a range of brand such Sony Ericsson Mobile, acronyms such as neologism EVJF (Enterrement de Vie de Jeune Fille) in French which means: funeral of the life of the young girl in English language and acronyms such as the term 'SICAV' (Investment Company with Variable Capital). The very nature of the dictionary says 'collaborative dictionary' can be announced as a specialised dictionary, and being, in fact, a general dictionary of language. The Urban Dictionary is an online collaborative dictionary in English. Wikipedia it as 'being the unofficial authority of the definitions of slang on the Internet.' We find a particular paradigm of terms constructed with the privative prefix 'de' as the verbal neologism 'to defriend' meaning: Someone to remove from your Livejournal, MySpace, Facebook or other social networking site, which could be translated by the neologism French language: se 'désamifier'.

Unlike the digital society, one of the characteristics of civil society is the compartmentalisation between the various groups that constitutes it. For example, the transfer of expert status of an area of expertise to another is possible only if the subject concerned can demonstrate his mastery of real expertise through of diplomas, of a professional experience and of recognition from his peers. Also the positioning of the individual in front of the representations it may have on the Internet and of civil society in which he lives, has an influence that is reflected in social practices underway in the first case (the internet), but which are unthinkable in the second case (civil society). Regarding the phenomenon of representation of objects in the world including know-how as praxis, Chauchat mentions that representations 'build a symbolic universe, which allows subjects to be situated, to identify, think and interpret that they live', they also cover:" the development of knowledge, which allows you to name, define, interprets different aspects of everyday reality'. As for Hogue, Levesque and Morin, they have of this concept a different approach: If there are unconscious fantasies in a group, there are also conscious representations of relationships and people. Through perceptual processes, cognitive and emotional messages of the organisation and of its operation which are successively processed and used to form a representation or a mental image of the medium. The representation thus obtained is neither true nor complete. It is actually a plausible approximation of the real life of the organisation, as it depends in part on values, beliefs and intentions of the individual' [16]. Civil society is built on rules that manage the status and position of individuals and groups within it. As Martin mentions: 'the fact to evolve between formal and informal groups, the Internet user has a status continually redefined within which it develops or not a sense of ownership with the group' a phenomenon that in dictionaries called 'collaborative dictionary' enables him to assume the status of the lexicographer. Finally, the digital space would it not composed of the interpenetration of the territories of such private space often located where the Internet user accesses to the media, the symbolic distance between the user and his interlocutors, depending on an artifact: the microcomputer which determines a physical distance almost common to all users? Does this common distance might not highlight some social practices born in the private space, but which take place in the digital society and which open thus a space of freedom?

\section{References}

1. Hogue JP, Lévesque D, Estelle M, Morin (1988) Group, power and communication. Montreal: Presses of the University of Quebec.

2. Mintzberg, Henry (1982) Structure and dynamics of organizations. Paris The Publishing Organization. 
Citation: Martin M (2017) From Status of Experts to Status of Surfers: A New Approach of Social Practices on the Internet. J Ment Disord Treat 3: 1000147. doi:10.4172/2471-271X.1000147

Page 7 of 7

3. Morgan, Gareth (1989) Pictures of the organization. Laval: Eska Publishing.

4. Benabou C, Abravanel H (1986) The behavior of individuals and groups in the organization.

5. Miller PM, Laflamme M (1987) Human Dynamism in Organizational Excellence.

6. Dionne, Pierre (2004) Taking the Leadership of Skills - The Awakening of Management.

7. Frydel, Yves (2006) "Everyday Internet: one in four French people".

8. Chauchat H, Delvigne AD (1999) From the identity of the subject to the social link. Paris: PUF

9. Hall, Edward T (1971) The hidden dimension Paris Threshold.

10. Mark, Rudolph T (1999) Internet, surf with ease on the largest network in the world. Paris.

11. Marcienne M (2006) A Name To Exist The Example of the Pseudonym on the Internet. Cambridge: Cambridge Scholars Publishing.

12. Corraze, Jacques (1980) Non-verbal communications. Paris.

13. Orecchioni K, Catherine (1996) La conversation. Paris Seuil.

14. Proulx, Serge (2004) The Internet revolution in question. Montreal Quebec America.

15. Marcienne M (2007) The language on the Internet, an ancient know-how digitized. Paris L'Harmattan.

16. Hogue JP, Lévesque D, Estelle M (1988) Morin, Group, power and communication. Montreal: Presses of the University of Quebec.
17. Rey, Alain DIR (2006) Historical dictionary of the French language by Robert (edn,) Paris.

18. (2006) The pseudonym on the Internet an appointment located at the crossroads of anonymity and privacy. Paris L'Harmattan.

19. http://www.cambridgescholars.com/a-name-to-exist

20. http://atilf.atilf.fr/

21. http://dictionnaire.reverso.net/francais-definition/ rembordagerembordage

22. http://jargonf.org/

23. http://jargonf.org/wiki/Jargonf:Accueil

24. http://jargonforg/wiki/alphabarre

25. http://jargonf.org/wiki/baladodiffusion

26. http://jargonf.org/wiki/balladodiffusion

27. http://jargonf.org/wiki/GETA

28. http://fr.wikipedia.org/wiki/Accueil.

29. http://fr.wikipedia.org/wiki/Travail_collaboratif

30. http://fr.wikipedia.org/wiki/Urban_Dictionary

31. http://www.dicodunet.com/

32. http://www.ecrans.fr/Arrete-ou-je-te-desamifie,8559.html

33. http://www.urbandictionary.com/define.php?term=defriend 